\title{
Multi-Optimization of Ultrasonic-Assisted Enzymatic Extraction of Atratylodes macrocephala Polysaccharides and Antioxidants Using Response Surface Methodology and Desirability Function Approach
}

\author{
Jin-Bao Pu ${ }^{1,2, \dagger}$, Bo-Hou Xia ${ }^{3,+}$, Yi-Juan Hu ${ }^{1,2}$, Hong-Jian Zhang ${ }^{1,2}$, Jing Chen ${ }^{4}$, Jie Zhou ${ }^{1,2}$, \\ Wei-Qing Liang ${ }^{1,2}$ and Pan $\mathrm{Xu}{ }^{1,2, *}$ \\ Received: 14 October 2015 ; Accepted: 4 December 2015 ; Published: 11 December 2015 \\ Academic Editor: Derek J. McPhee \\ 1 Development and Research Center of Official Silkworm Resources, Zhejiang Academy of Traditional \\ Chinese Medicine, Hangzhou 310007, China; pjb0225@163.com (J.-B.P.); huyijuan604@163.com (Y.-J.H.); \\ jian871211@sina.com (H.-J.Z.); Kenzei@163.com (J.Z.); jxlwq22@163.com (W.-Q.L.) \\ 2 Key Laboratory of Research and Development of Chinese Medicine of Zhejiang Province, \\ Hangzhou 310007, China \\ 3 College of Pharmacy, Hunan Chinese Medical University, Changsha 410208, China; xiabohou@163.com \\ 4 College of Life Science, Zhejiang Chinese Medical University, Hangzhou 310015, China; \\ cj00123@zcmu.edu.cn \\ * Correspondence: xpan840520@163.com; Tel.: +86-571-8884-9079 (ext. 123); Fax: +86-571-8884-5196 \\ + These authors contributed equally to this work.
}

\begin{abstract}
Rhizoma Atractylodes macrocephala polysaccharides (RAMP) have been reported to have a variety of important biological activities. In this study, an ultrasonic-assisted enzymatic extraction (UAEE) was employed to obtain the highest extraction yield and strongest antioxidant activity of RAMP and optimized by a multi-response optimization process. A three-level four-factor Box-Behnken design (BBD) was performed as response surface methodology (RSM) with desirability function (DF) to attain the optimal extraction parameters. The DPPH scavenging percentage was used to represent the antioxidant ability of RAMP. The maximum D value (0.328), along with the maximum yield (59.92\%) and DPPH scavenging percentage $(13.28 \%)$ were achieved at $90.54 \mathrm{~min}$, $57.99{ }^{\circ} \mathrm{C}, 1.95 \%$ cellulase and $225.29 \mathrm{~W}$. These values were further validated and found to be in good agreement with the predicted values. Compared to the other extraction methods, both the yield and scavenging percentage of RAMP obtained by UAEE was favorable and the method appeared to be time-saving and of high efficiency. These results demostrated that UAEE is an appropriate and effective extraction technique. Moreover, RSM with DF approach has been proved to be adequate for the design and optimization of the extraction parameters for RAMP. This work has a wide range of implications for the design and operation of polysaccharide extraction processes.
\end{abstract}

Keywords: Rhizoma Atractylodes macrocephala polysaccharides; ultrasonic-assisted enzymatic extraction; response surface methodology; desirability function approach; antioxidant activity; multi-optimization

\section{Introduction}

Rhizoma Atractylodes macrocephala (RAM) is the dried rhizome of Atractylodes macrocephala Koidz, which belong to the family Asteraceae (Compositae), found mainly distributed in China, Japan, and Korea [1]. RAM is widely used for the treatment of splenic asthenia, anorexia, oedema, excessive 
perspiration and abnormal fetal movement [2]. The rhizomes of Atractylodes macrocephala are rich in sesquiterpenes, polyacetylenes, phenylpropanoids, coumarins, glycosides and polysaccharides [1,3-6]. Recently, interest in Rhizoma Atractylodes macrocephala polysaccharides (RAMP) has been growing, because of the various bioactivities of RAMP, including immune response stimulating [7-9], aging defying [10], neuroprotective effects [11], hyperglycemic activity [12] and protective effects against liver ischemia reperfusion injury [13]. Most of the aforementioned activities are related with antioxidant properties and polysaccharides are widely considered to be a strong antioxidants.

However, little attention has been paid to the effective extraction of RAMP. Conventionally, polysaccharides are extracted by refluxing in hot water, which is often time-consuming, gives low yields of polysaccharides and even results in the loss of some of the pharmacological activity [14]. In recent years, various methods have been developed for the extraction of polysaccharides, such as ultrasonic-assisted extraction (UAE) and enzyme-assisted extraction (EAE). Among them, UAE is a rapid, energy efficient method that gives high extraction yields and has a minimal impact on the bioactivities [15]. Also, with the additional of specific enzymes such as cellulase and proteases, EAE can promote the release of intracellular contents by breaking the cell wall and lipid bodies [16]. Thus, it is considered as a mild, efficient and environmentally friendly extraction method, which has been used recently in the extraction of various kinds of compounds [17]. In this study, to achieve a high yield extraction and maximize the antioxidant ability of RAMP we combined the advantages of the UAE and EAE methods, in what is defined as ultrasonic-assisted enzymatic extraction (UAEE).

Response surface methodology (RSM) is an effective tool for optimizing experimental processes when many factors and interactions may affect the response variables [18]. Most of the work on RSM has been focused on the case where there is only one response of interest $[15,17]$. As a matter of fact, in many situations there are several response variables of interest or the relationship between the response variables and design variables is too complex to be efficiently estimated using traditional surface fitting approaches [19]. In this case, determination of the optimum settings on design variables would require simultaneous consideration of all the response [20], which is called a multi-response optimization (MRO).

Many creative methods have been developed for MRO, and the general purpose of these methods is to convert the MRO problem into a single aggregated objective function and then construct an efficient algorithm to find the optimum solution [21]. Presently, desirability function (DF) is a popular and established technique for the simultaneous determination of optimum settings of variables for multiple responses. It was first developed by Harrington and modified by Derringer and Suich [22,23]. It has been successfully used to optimize several multi-response cases, and its functions and advantages has been discussed in different articles [24-26].

However, the feasibility of using UAEE for RAMP and the multi-response optimization of the UAEE procedure by RSM mated with DF have not yet been explored in the literature. There is no research to emphasize the wide range of approaches that can be employed and the great impact on the polysaccharide extraction industries. Hence, this work aim to apply the UAEE method for the high yield and antioxidant activities of RAMP, and to find the optimal extraction condition using the RSM with DF approach in order to ensure rational utilization.

\section{Results and Discussion}

\subsection{Single Factor Experimental Analysis of UAEE}

All the factors that may affect the process must be carefully determined and examined. The experimental domain must be defined for each factor and also a control and measurement method must be established [27]. Thus, it is necessary to carry out single factor experiments to determine the experimental variables and interactions that have a significant influence on one or several responses. In this study, according to the priminary experiments, four major influencing factors, 
including extraction time, extraction temperature, cellulase concentration and ultrasonic power were selected for the next experiments.

\subsubsection{Effect of Extraction Time on the Yield of RAMP}

Generally speaking, the longer the extraction time, the higher the yield of polysaccharides [28]. The effect of extraction time on extraction yield of RAMP is shown in Figure 1a. The yield of RAMP continued to increase gradually over the extraction time range of 10-70 $\mathrm{min}$, until it reached its highest point at $70 \mathrm{~min}$, which indicated that the polysaccharides were fully extracted as time goes by. When the extraction time reached $90 \mathrm{~min}$, the increase in the yield of RAMP eased steadily. This phenomenon can be attributed to polysaccharide hydrolysis during the extended extraction [17].

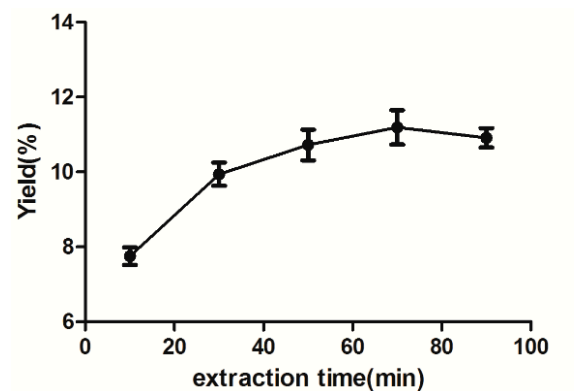

(a)

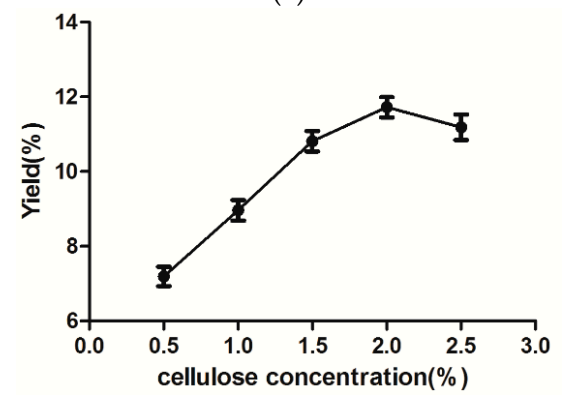

(c)

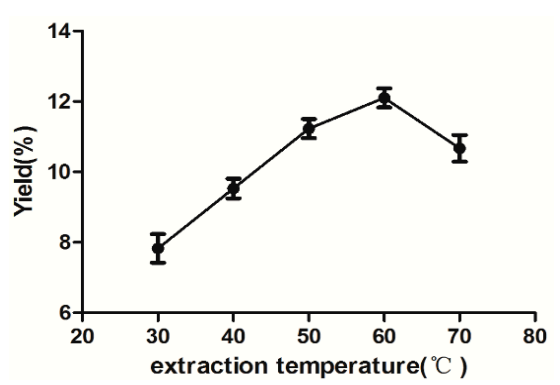

(b)

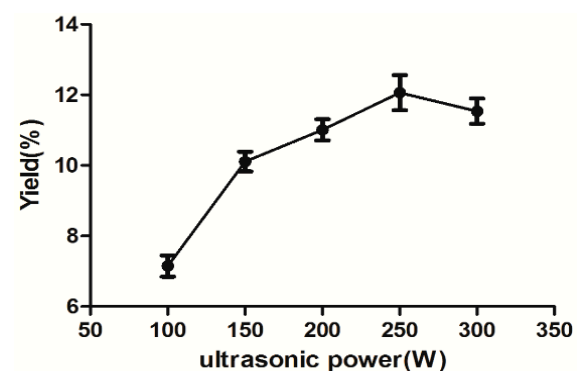

(d)

Figure 1. Effects of extraction time (a) extraction temperature (b) cellulase concentration (c) and ultrasonic power (d) on the extraction yield of RAMP (\%).

\subsubsection{Effect of Extraction Temperature on the Yield of RAMP}

The extraction temperature is an important factor influencing the extraction yield. As shown in Figure $1 \mathrm{~b}$, the yield of RAMP was significantly increased when the temperature was increased from 30 to $60^{\circ} \mathrm{C}$, and reached a peak value of $8.07 \%$. Then further increase of extraction temperature resulted in a RAMP.extraction yield decease. One possible explanation is that the polysaccharides may be hydrolyzed at a high temperature [29], and the another reason is the activity of enzyme added to the solution were heavily influenced by the temperature, as enzyme activity is well known to be reduced when the temperature is too low or too high [30].

\subsubsection{Effect of Cellulase Concentration on the Yield of RAMP}

Much research has shown that different cellulase concentrations will significantly affect the yield of polysaccharides [31,32]. As shown in Figure 1c the cellulase concentrationcurve indicated that the first increase of enzyme concentration lead to an obvious RAMP extraction yield increase till $2.0 \%$, and then began to decrease slightly. This indicated that a $2.0 \%$ amount of enzyme was sufficient to obtain a high polysaccharide yield. Taking cellulase consumption and the yield of RAMP into account, the enzyme concentration of $2.0 \%$ was high enough for the UAEE. 


\subsubsection{Effect of Ultrasonic Power on the Yield of RAMP}

Ultrasonic power is a critical parameter in the UAEE method. Its effect on the extraction yield of RAMP is shown in Figure 1d. The yield increased as ultrasonic power increased from $100 \mathrm{~W}$ to $250 \mathrm{~W}$, and decined when it went up to $300 \mathrm{~W}$. The maximum extraction yield of RAMP was observed when the ultrasonic power was $250 \mathrm{~W}$. A possible explaination is that the polysaccharides' diffusion coefficient and the solubility of the polysaccharides in the extracting solvent increased with the enhanced ultrasonic power, and this eventually caused an incease in the amount of polysaccharide going out from the rhizome of Atractylodes macrocephala into solution [33]. After reaching the peak, the polysaccharide yield droped because of the loss during ultrasonicated post-processing [29]. To summarize the single-factor studies, the following conditions could used for the response surface methodology experiments: an extraction time of $10-90 \mathrm{~min}$, an extraction temperature of $30-70{ }^{\circ} \mathrm{C}$, a cellulase concentration of $0.5 \%-2.5 \%$ and a ultrasound power of $100-300 \mathrm{~W}$.

\subsection{Multi-Response Design and Analysis}

\subsubsection{Statistical Analysis and Model Fitting}

The yield of RAMP in the BBD experiments

As seen in Table 1, the results showed that the yield of polysaccharide $\left(\mathrm{Y}_{1}\right)$ ranged from $7.22 \%$ to $13.10 \%$.

Table 1. BBD matrix and response values for extraction yield and DPPH scavenging percentage of RAMP as well as D value.

\begin{tabular}{|c|c|c|c|c|c|c|c|}
\hline Run & $X_{1}$ & $X_{2}$ & $X_{3}$ & $X_{4}$ & $Y_{1}{ }^{a}(\%)$ & $Y_{2}{ }^{a}(\%)$ & D Value \\
\hline 1 & 10 & 50 & 0.5 & 200 & $8.60 \pm 0.63$ & $39.11 \pm 3.07$ & 0.167 \\
\hline 2 & 50 & 70 & 1.5 & 100 & $10.37 \pm 0.52$ & $50.51 \pm 2.42$ & 0.243 \\
\hline 3 & 50 & 50 & 1.5 & 200 & $12.98 \pm 0.64$ & $63.13 \pm 2.56$ & 0.337 \\
\hline 4 & 50 & 50 & 1.5 & 200 & $12.93 \pm 0.65$ & $63.26 \pm 3.16$ & 0.336 \\
\hline 5 & 90 & 50 & 1.5 & 300 & $12.18 \pm 0.62$ & $54.16 \pm 3.79$ & 0.287 \\
\hline 6 & 50 & 50 & 1.5 & 200 & $13.10 \pm 0.59$ & $63.87 \pm 3.27$ & 0.342 \\
\hline 7 & 50 & 70 & 1.5 & 300 & $12.54 \pm 0.60$ & $57.74 \pm 2.46$ & 0.308 \\
\hline 8 & 50 & 70 & 0.5 & 200 & $10.37 \pm 0.57$ & $46.60 \pm 2.03$ & 0.227 \\
\hline 9 & 10 & 50 & 1.5 & 300 & $11.12 \pm 0.70$ & $48.70 \pm 1.94$ & 0.247 \\
\hline 10 & 90 & 70 & 1.5 & 200 & $12.15 \pm 0.50$ & $56.10 \pm 2.58$ & 0.295 \\
\hline 11 & 10 & 70 & 1.5 & 200 & $10.96 \pm 0.56$ & $48.23 \pm 2.95$ & 0.243 \\
\hline 12 & 90 & 30 & 1.5 & 200 & $9.62 \pm 0.71$ & $46.13 \pm 2.69$ & 0.213 \\
\hline 13 & 50 & 30 & 1.5 & 300 & $10.35 \pm 0.63$ & $51.13 \pm 2.71$ & 0.245 \\
\hline 14 & 50 & 30 & 1.5 & 100 & $7.54 \pm 0.55$ & $42.29 \pm 2.10$ & 0.162 \\
\hline 15 & 50 & 50 & 1.5 & 200 & $12.99 \pm 0.72$ & $63.88 \pm 2.08$ & 0.340 \\
\hline 16 & 50 & 50 & 1.5 & 200 & $13.06 \pm 0.70$ & $63.51 \pm 2.04$ & 0.339 \\
\hline 17 & 10 & 50 & 2.5 & 200 & $10.84 \pm 0.59$ & $49.07 \pm 3.00$ & 0.244 \\
\hline 18 & 10 & 50 & 1.5 & 100 & $8.21 \pm 0.74$ & $41.75 \pm 2.99$ & 0.172 \\
\hline 19 & 50 & 30 & 2.5 & 200 & $10.67 \pm 0.58$ & $49.64 \pm 3.20$ & 0.244 \\
\hline 20 & 50 & 50 & 2.5 & 300 & $12.75 \pm 0.50$ & $55.66 \pm 2.71$ & 0.302 \\
\hline 21 & 90 & 50 & 2.5 & 200 & $12.91 \pm 0.72$ & $55.63 \pm 3.89$ & 0.305 \\
\hline 22 & 50 & 30 & 0.5 & 200 & $7.22 \pm 0.53$ & $42.47 \pm 3.26$ & 0.157 \\
\hline 23 & 50 & 50 & 0.5 & 100 & $7.45 \pm 0.50$ & $39.72 \pm 2.23$ & 0.151 \\
\hline 24 & 50 & 50 & 2.5 & 100 & $10.83 \pm 0.51$ & $51.88 \pm 2.91$ & 0.256 \\
\hline 25 & 90 & 50 & 1.5 & 100 & $9.95 \pm 0.70$ & $48.11 \pm 2.58$ & 0.226 \\
\hline 26 & 50 & 50 & 0.5 & 300 & $10.43 \pm 0.45$ & $50.52 \pm 3.23$ & 0.244 \\
\hline 27 & 90 & 50 & 0.5 & 200 & $9.11 \pm 0.67$ & $45.91 \pm 3.40$ & 0.203 \\
\hline 28 & 50 & 70 & 2.5 & 200 & $12.51 \pm 0.50$ & $59.84 \pm 2.66$ & 0.316 \\
\hline 29 & 10 & 30 & 1.5 & 200 & $8.29 \pm 0.80$ & $43.83 \pm 2.65$ & 0.181 \\
\hline
\end{tabular}

${ }^{a}$ each value is the mean of triplicate measurements. 
Multiple regression analysis was performed to build a mathematical model to find the optimum conditions that maximize the extraction yield of RAMP and study the relationship of the response variable and test variable. The second-order polynomial equation was given by the following expression:

$$
\begin{aligned}
& Y_{1}=13.01+0.66 X_{1}+1.27 X_{2}+1.44 X_{3}+1.25 X_{4}-0.035 X_{1} X_{2}+0.39 X_{1} X_{3}-0.17 X_{1} X_{4}- \\
& 0.33 X_{2} X_{3}-0.16 X_{2} X_{4}-0.27 X_{3} X_{4}-1.30 X_{1}^{2}-1.47 X_{2}^{2}-1.34 X_{3}^{2}-1.33 X_{4}^{2}
\end{aligned}
$$

The analysis of variance (ANOVA), goodness-of-fit and the adequacy of the regression model were summarized in Table 2. The high model $F$-value and the low $P$-value indicates the level of confidence of the selected model [20]. The model $F$-value of 1337.56 and the associated lower $p$-value $(p<0.0001)$ implied the model was highly statistically significant. There was only a $0.01 \%$ chance that a "Model $F$-value" this large could occur due to noise. The value of $\mathrm{R}^{2}$ reflects the proportion of variation in the response attributed to the model rather than to random error [34]. The model has shown a good fit with the high $R^{2}$ value and adjusted determination coefficient $\left(R^{2}\right.$ adj $)$ of 0.9993 and 0.9985 , respectively. This confirmed that only $0.07 \%$ of the total variation is not explained and the experimental data were well fitted by the model. What's more, the coefficient of the variation (C.V.) refer to the ratio of the standard error (SD) of estimated data to the mean value of the observed response [20]. In this model, the C.V. of $0.68 \%$ indicates that the simulation can be considered as resonably reproducible, which also means the precision and the experimental values of the model were of reliability. Table 2 also reveals that the interaction of extraction time and extraction temperature was insignificant $(p>0.05)$, while all other model terms were highly significant $(p<0.01)$. The results indicated that the linear coefficients $\left(X_{1}, X_{2}, X_{3}, X_{4}\right)$, quadratic term coefficients $\left(X_{1}^{2}, X_{2}{ }^{2}, X_{3}{ }^{2}, X_{4}{ }^{2}\right)$ and cross product coefficients $\left(X_{1} \cdot X_{3}\right.$, $\left.\mathrm{X}_{1} \cdot \mathrm{X}_{4}, \mathrm{X}_{2} \cdot \mathrm{X}_{3}, \mathrm{X}_{2} \cdot \mathrm{X}_{4}, \mathrm{X}_{3} \cdot \mathrm{X}_{4}\right)$ were all significantly correlated with the RAMP extraction yield $(p<0.01)$.

Table 2. ANOVA for dependent variable: the yield of RAMP.

\begin{tabular}{cccccc}
\hline Source & Sum of Squares & df & Mean Square & F & Sig. (Prob $>$ F) \\
\hline Corrected model & 100.64 & 14 & 7.19 & 1337.56 & $<0.0001$ \\
$\mathrm{X}_{1}$ & 5.20 & 1 & 5.20 & 967.75 & $<0.0001$ \\
$\mathrm{X}_{2}$ & 19.28 & 1 & 19.28 & 3587.29 & $<0.0001$ \\
$\mathrm{X}_{3}$ & 25.03 & 1 & 25.03 & 4656.98 & $<0.0001$ \\
$\mathrm{X}_{4}$ & 18.80 & 1 & 18.80 & 3498.22 & $<0.0001$ \\
$\mathrm{X}_{1} \mathrm{X}_{2}$ & $<0.0001$ & 1 & $<0.0001$ & 0.91 & 0.3558 \\
$\mathrm{X}_{1} \mathrm{X}_{3}$ & 0.61 & 1 & 0.61 & 113.21 & $<0.0001$ \\
$\mathrm{X}_{1} \mathrm{X}_{4}$ & 0.12 & 1 & 0.12 & 21.51 & 0.0004 \\
$\mathrm{X}_{2} \mathrm{X}_{3}$ & 0.43 & 1 & 0.43 & 79.83 & $<0.0001$ \\
$\mathrm{X}_{2} \mathrm{X}_{4}$ & 0.10 & 1 & 0.10 & 19.05 & 0.0006 \\
$\mathrm{X}_{3} \mathrm{X}_{4}$ & 0.28 & 1 & 0.28 & 52.27 & $<0.0001$ \\
$\mathrm{X}_{1}{ }^{2}$ & 11.03 & 1 & 11.03 & 2052.10 & $<0.0001$ \\
$\mathrm{X}_{2}{ }^{2}$ & 14.07 & 1 & 14.07 & 2617.62 & $<0.0001$ \\
$\mathrm{X}_{3}{ }^{2}$ & 11.56 & 1 & 11.56 & 2151.64 & $<0.0001$ \\
$\mathrm{X}_{4}{ }^{2}$ & 11.50 & 1 & 11.50 & 2139.57 & $<0.0001$ \\
Residual & 0.075 & 14 & $<0.0001$ & & \\
Lack of fit & 0.057 & 10 & $<0.0001$ & 1.25 & 0.4493 \\
Pure error & 0.018 & 4 & $<0.0001$ & & \\
Cor total & 100.71 & 28 & & & \\
$\mathrm{R}^{2}$ & 0.9993 & SD & 0.60 & & \\
$\mathrm{R}^{2}$ adj & 0.9985 & $\mathrm{C} . \mathrm{V} . \%$ & 0.68 & & \\
Adeq precision & 110.900 & & & & \\
\hline & & & & \\
\hline
\end{tabular}

Response surfaces were plotted by the Design Expert software to explain the interactions of the variables for the maximum response. The corresponding three-dimensional response surfaces are shown in Figure 2. Each figure shows the effects of two factors at a time on the polysaccharide 
yield while all other factors were kept at zero level. Figure 2a illustrates the polysaccharide yield in response to extraction time and extraction temperature at a fixed ultrasound power of $200 \mathrm{~W}$ and a fixed celluose cncentration of $1.5 \%$. The yield was very low at low extraction time and temperature, and increased as extraction time and extraction temperature increased until a peak value was reached. Further increasing the extraction time and temperature led to a decreased polysaccharide yield. Similar trends were observed for the effects of extraction time and cellulase concentration (Figure $2 b$ ), of extraction time and ultrasonic power (Figure 2c), of cellulase concentration and extraction temperature (Figure 2d), of ultrasonic power and extraction temperature (Figure 2e) and of ultrasonic power and cellulase concentration (Figure 2f). According to the model, the maximum yield of RAMP was $13.93 \%$ and the corresponding variables values were obtained after an extraction time of $61.91 \mathrm{~min}$, at an extraction temperature of $56.99{ }^{\circ} \mathrm{C}$, using a cellulase concentration of $2.00 \%$ and $237.96 \mathrm{~W}$ of ultrasonic power.

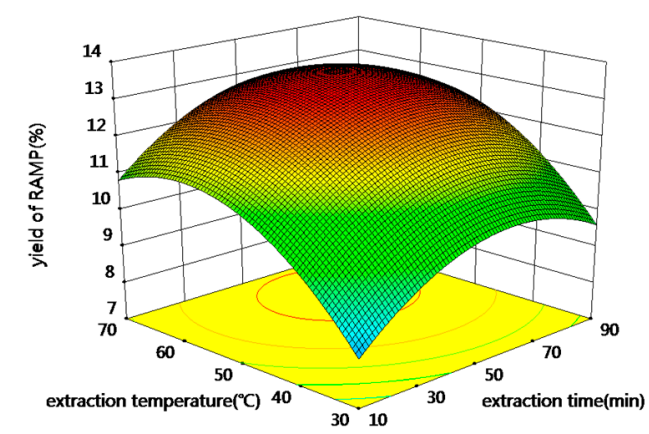

(a)

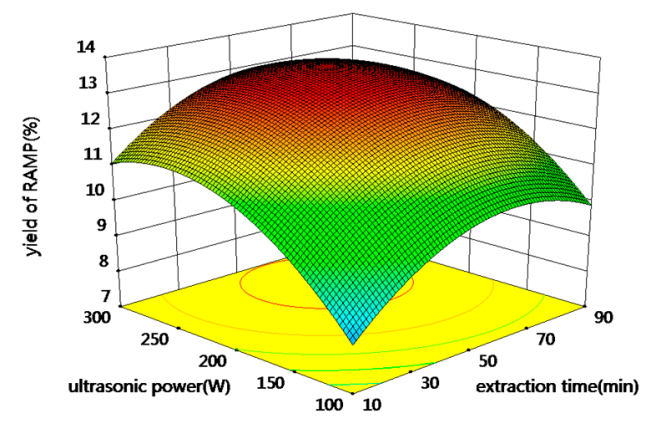

(c)

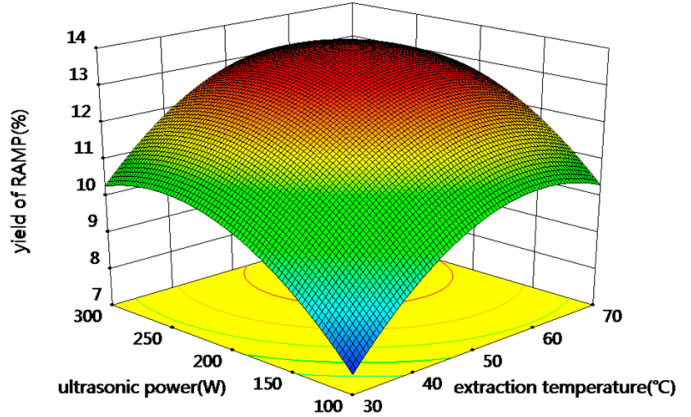

(e)

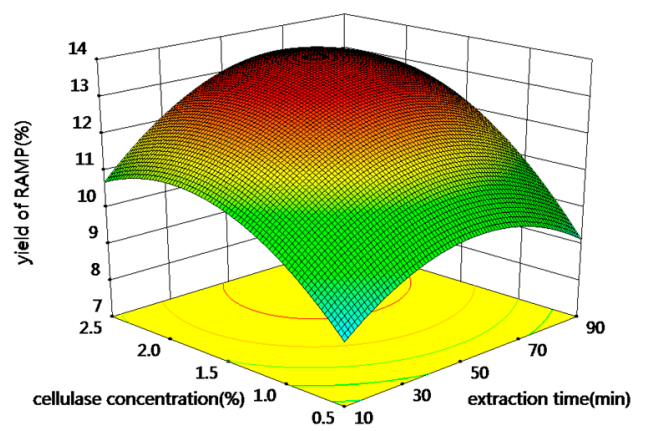

(b)

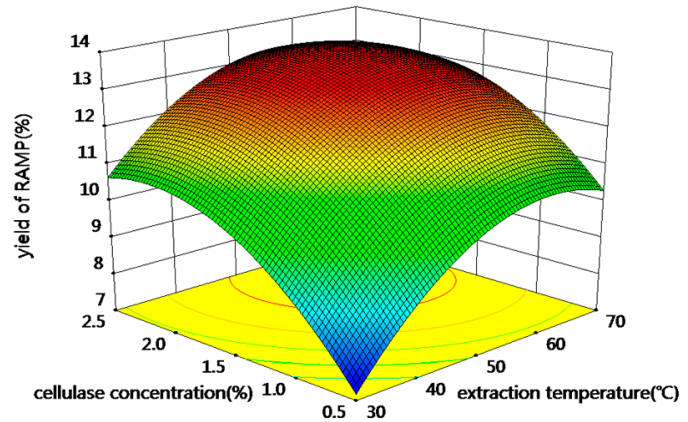

(d)

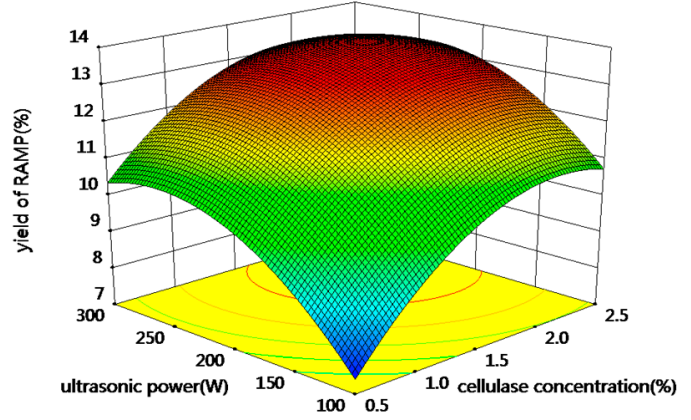

(f)

Figure 2. Response surface (3D) showing the effect of extraction parameters on extraction yield of RAMP. (a) extraction time and temperature; (b) extraction time and cellulase concentration; (c) extraction time and ultrasonic power; (d) extraction temperature and cellulase concentration; (e) extraction temperature and ultrasonic power; (f) cellulase concentration and ultrasonic power. 
The DPPH Scavenging Percentage of RAMP in the BBD Experiments

As seen in Table 1, the DPPH scavenging percentage of RAMP $\left(\mathrm{Y}_{2}\right)$ ranged from $39.11 \%$ to $63.88 \%$. The data were analyzed by multiple regression analysis to get the following second-order polynomial equation:

$$
\begin{aligned}
& Y_{2}=63.53+2.95 X_{1}+3.63 X_{2}+4.78 X_{3}+3.64 X_{4}+1.39 X_{1} X_{2}-0.06 X_{1} X_{3}-0.23 X_{1} X_{4}+ \\
& 1.52 X_{2} X_{3}-0.40 X_{2} X_{4}-1.76 X_{3} X_{4}-8.62 X_{1}^{2}-6.40 X_{2}^{2}-7.46 X_{3}^{2}-6.69 X_{4}^{2}
\end{aligned}
$$

ANOVA results of the quadratic model presented in Table 3 show a high $\mathrm{R}^{2}$ of 0.9973 and a low C.V. value of $1.08 \%$, demonstrating that the model can adequately describe the response surface of DPPH scavenging percentage. The high model $F$-value (376.23) and low $p$-value $(p<0.0001)$ suggested the results were highly statistically significant and had a good fit of the model. It can be seen from Table 3 that all the linear coefficients $\left(X_{1}, X_{2}, X_{3}, X_{4}\right)$, quadratic term coefficients $\left(X_{1}{ }^{2}, X_{2}{ }^{2}, X_{3}{ }^{2}, X_{4}{ }^{2}\right)$ and cross product coefficients $\left(X_{1} \cdot X_{2}, X_{2} \cdot X_{3}, X_{3} \cdot X_{4}\right)$ were significant model terms, with very small $p$ value $(p<0.001)$. Moreover, the coefficients of $X_{1} \cdot X_{3}, X_{1} \cdot X_{4}, X_{2} \cdot X_{4}$ were found non-significant $(p>0.05)$.

Table 3. ANOVA for the dependent variable: the DPPH scavenging percentage of RAMP.

\begin{tabular}{cclccc}
\hline Source & Sum of Squares & df & Mean Square & $\boldsymbol{F}$ & Sig. (Prob $>\boldsymbol{F}$ ) \\
\hline Corrected model & 1629.04 & 14 & 116.36 & 376.23 & $<0.0001$ \\
$\mathrm{X}_{1}$ & 104.14 & 1 & 104.14 & 336.70 & $<0.0001$ \\
$\mathrm{X}_{2}$ & 157.91 & 1 & 157.91 & 510.55 & $<0.0001$ \\
$\mathrm{X}_{3}$ & 274.47 & 1 & 274.47 & 887.43 & $<0.0001$ \\
$\mathrm{X}_{4}$ & 158.78 & 1 & 158.78 & 513.37 & $<0.0001$ \\
$\mathrm{X}_{1} \mathrm{X}_{2}$ & 7.76 & 1 & 7.76 & 25.08 & 0.0002 \\
$\mathrm{X}_{1} \mathrm{X}_{3}$ & 0.014 & 1 & 0.014 & 0.047 & 0.8323 \\
$\mathrm{X}_{1} \mathrm{X}_{4}$ & 0.20 & 1 & 0.20 & 0.65 & 0.4320 \\
$\mathrm{X}_{2} \mathrm{X}_{3}$ & 9.21 & 1 & 9.21 & 29.78 & $<0.0001$ \\
$\mathrm{X}_{2} \mathrm{X}_{4}$ & 0.65 & 1 & 0.65 & 2.10 & 0.1698 \\
$\mathrm{X}_{3} \mathrm{X}_{4}$ & 12.32 & 1 & 12.32 & 39.83 & $<0.0001$ \\
$\mathrm{X}_{1}{ }^{2}$ & 482.07 & 1 & 482.07 & 1558.67 & $<0.0001$ \\
$\mathrm{X}_{2}{ }^{2}$ & 265.55 & 1 & 265.55 & 858.60 & $<0.0001$ \\
$\mathrm{X}_{3}{ }^{2}$ & 360.58 & 1 & 360.58 & 1165.86 & $<0.0001$ \\
$\mathrm{X}_{4}{ }_{\text {Residual }}$ & 290.38 & 1 & 290.38 & 938.89 & $<0.0001$ \\
Lack of fit & 4.33 & 14 & 0.31 & & \\
Pure error & 3.86 & 10 & 0.39 & 3.27 & 0.1321 \\
Cor total & 0.47 & 4 & 0.12 & & \\
$\mathrm{R}^{2}$ & 1633.37 & 28 & & & \\
$\mathrm{R}^{2}$ adj & 0.9973 & $\mathrm{SD}$ & 0.56 & & \\
Adeq precision & 0.9947 & $\mathrm{C} . \mathrm{V} . \%$ & 1.08 & & \\
\hline & 60.809 & & & & \\
\hline
\end{tabular}

Figure 3a shows the DPPH scavenging percentage with varying extraction time and extraction temperature. From the figure, it can be seen that DPPH scavenging percentage increased as the extraction time and extraction temperature increased during the initial stage and then decreased slightly. Similar trends were observed for the other interactions of the model (Figure 3b-f). According to the model, the maximum DPPH scavenging percentage of $61.49 \%$ can be obtained after an extraction time of $85.53 \mathrm{~min}$, at an extraction temperature of $58.29^{\circ} \mathrm{C}$, with a cellulase concentration of $1.84 \%$ and $220.05 \mathrm{~W}$ of ultrasonic power. 


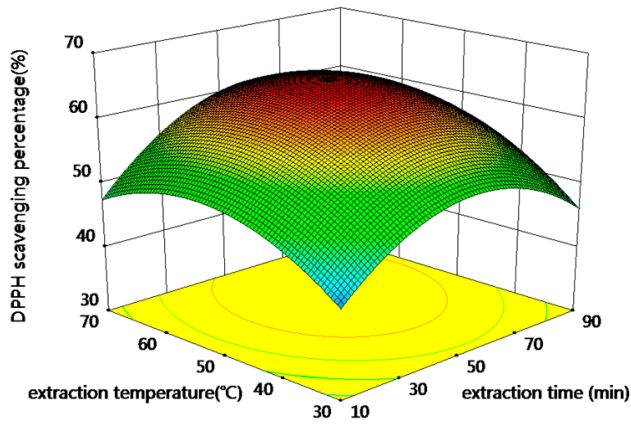

(a)

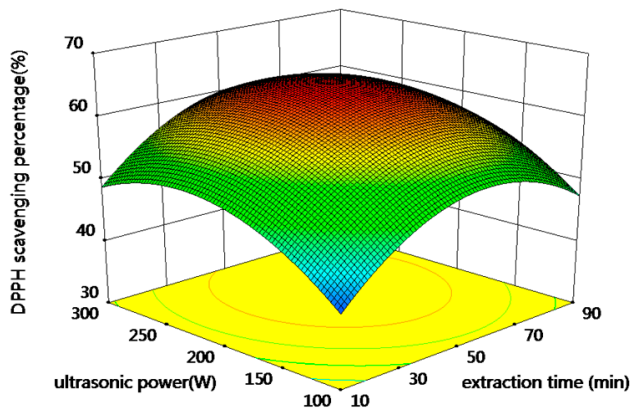

(c)

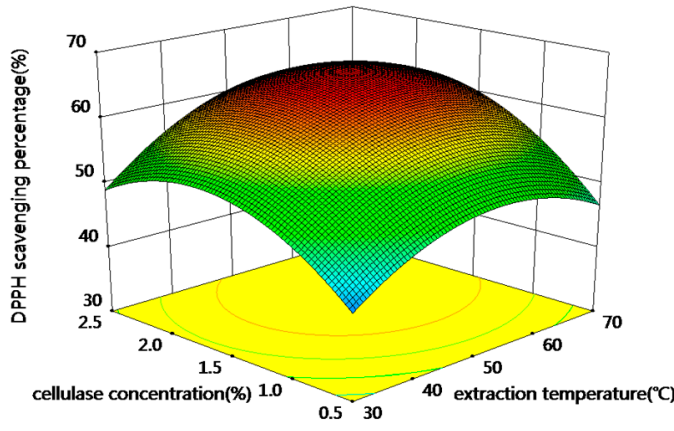

(e)

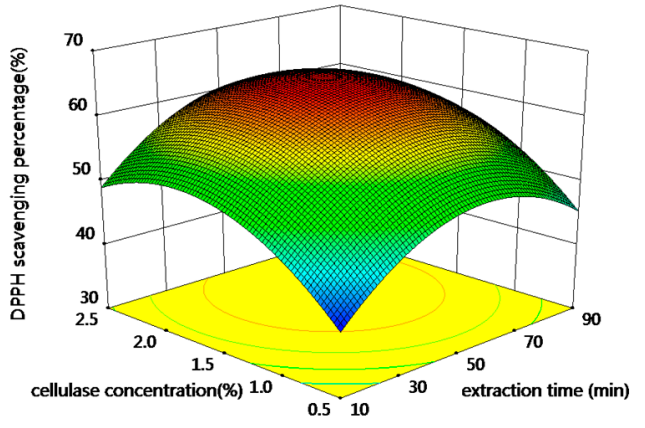

(b)

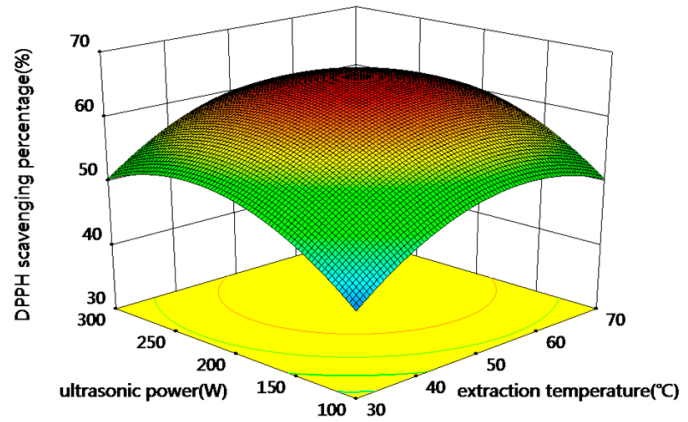

(d)

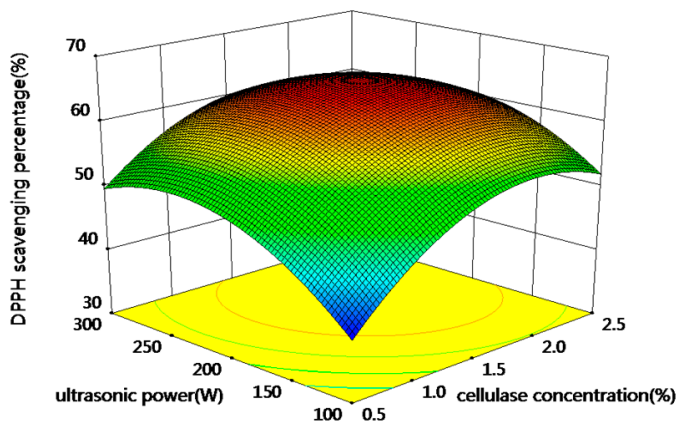

$(\mathbf{f})$

Figure 3. Response surface (3D) showing the effect of extraction parameters on DPPH scavenging percentage of RAMP. (a) extraction time and temperature; (b) extraction time and cellulase concentration; (c) extraction time and ultrasonic power; (d) extraction temperature and ultrasonic power; (e) extraction temperature and cellulase concentration; (f) cellulase concentration and ultrasonic power.

\subsubsection{Optimization Analysis of the UAEE Procedure}

According to the previous study, the maximum value of RAMP yield by HWE was 3.13\% [35]. We take the HWE maximum yield as our minimum polysaccharide yield in this study. The maximum value of the polysaccharide yield was specified as $50 \%$. Besides, the maximum theoretical value of the DPPH scavenging percentage of RAMP is 100\%, and the minimum DPPH scavenging percentage was specified as $20 \%$. Thus, a one-sided transform of polysaccharides yield $\left(d_{1}\right)$ and DPPH scavenging percentage $\left(d_{2}\right)$ is obtained as follows:

$$
d_{1}= \begin{cases}0 & Y_{i} \leqslant 3.13 \\ {\left[\frac{Y_{i}-3.13}{50-3.13}\right]} & 3.13<Y_{i}<50 \\ 1 & Y_{i} \geqslant 50\end{cases}
$$




$$
d_{2}= \begin{cases}0 & Y_{i} \leqslant 20 \\ {\left[\frac{Y_{i}-20}{100-20}\right]} & 20<Y_{i}<100 \\ 1 & Y_{i} \geqslant 100\end{cases}
$$

The overall desirability $D$ is calculated as:

$$
D=\sqrt{d_{1} d_{2}}
$$

By using $D$ as the new response, the optimum values of selected variables can be obtained through regression analysis. In this study, the optimal conditions for highest $D$ (with a $D$ value of 0.328 ) were: extraction time of $90.54 \mathrm{~min}$, extraction temperature of $57.99^{\circ} \mathrm{C}$, cellulase concentration of $1.95 \%$ and $225.29 \mathrm{~W}$ of ultrasonic power. The corresponding maximum polysaccharide yield and DPPH scavenging percentage were $13.28 \%$ and $59.92 \%$, respectively.

\subsubsection{Verification of the Predictive Model}

To confirm the suitability of the model equation, three confirmation experiments were conducted under the optimized conditions. Considering the operability in actual production, the optimal conditions were slightly modified as follows: extraction time $90 \mathrm{~min}$, extraction temperature $58^{\circ} \mathrm{C}$, cellulase concentration $1.95 \%$ and ultrasonic power $225 \mathrm{~W}$. Under these conditions, the experimental yield of RAMP was $13.18 \% \pm 0.56 \%(n=3)$ and the DPPH scavenging percentage was $60.19 \% \pm 2.99 \%$ $(n=3)$, which matched well with the predicted values of $13.28 \%$ and $59.92 \%$, respectively. This confirmed that the model was adequate for optimization of the UAEE process. As a result, RSM coupled with DF approach was considered to be an accurate and decisive tool for predicting the maximum extraction yield and highest antioxidant activity of RAMP using the UAEE technique.

\subsection{Comparison with Other Extraction Processes}

The results of our comparision with other extraction methods are illustrated in Figure 4. As shown in Figure 4a, the yield of RAM obtained by UAE and EAE was lower than that of UAEE for the same ratio of material and water, extraction time, temperature and $\mathrm{pH}$. In addition, the yield of RAMP obtained by UAEE under the optimal conditions in this study was much higher and obtained faster than with the traditional hot water treatment, which obtained a yield of $5.21 \%$ under the conditons of $90 \mathrm{~min}$ extraction time and $58^{\circ} \mathrm{C}$ temperature. When the extraction time was extended to $180 \mathrm{~min}$ and extraction temperature was went up to $80^{\circ} \mathrm{C}$, the RAMP yield by HWE rose to $8.35 \%$, but was still lower than that of UAEE (13.18\%). Consequently, UAEE has some obvious time-saving and high efficiency advantages when compared with other extraction processes. Figure $4 \mathrm{~b}$ shows the DPPH sacvenging percentage among all the extraction processes, which obviously display a similar trend as the yield of RAMP. Thus, it was confirmed that UAEE should be an appropriate and effective extraction technique for obtaining high yields and maximum antioxidant activity of RAMP. Also, the costs of technique is so low that it has a very good industrial application prospects.

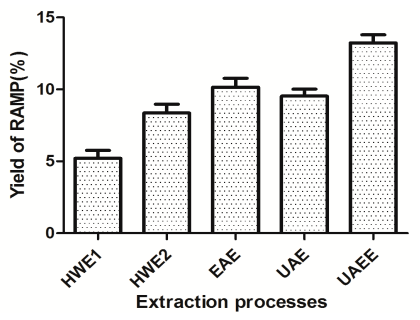

(a)

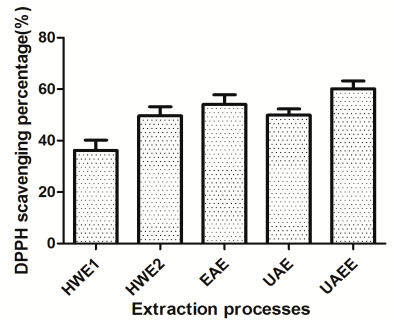

(b)

Figure 4. The yield (a) and DPPH scavenging percentage; (b) of RAMP of different extraction processes. 


\subsection{Preliminary Characterization of RAMP}

The total neutral carbohydrate content of RAMP obtained by UAEE under the optimal conditions was estimated at $76.34 \%$ by the phenol-sulfuric acid method. RAMP had a negative response to the Bradford method. No absorption was observed at $280 \mathrm{~nm}$ in the UV spectrum, which also indicates the absence of protein. Its uronic acid content was under the limit of detection. The FT-IR spectrum of RAMP is shown in Figure 5. A strong broad stretching peak at approximately $3377.80 \mathrm{~cm}^{-1}$ for hydroxyl group and a weak band at approximately $2925.55 \mathrm{~cm}^{-1}$ for the C-H stretching vibration were observed; these two absorption bands are typical characteristic absorptions of polysaccharides [36]. The relatively weak absorption peaks at $1633.04 \mathrm{~cm}^{-1}$ and $1407.05 \mathrm{~cm}^{-1}$ also suggest the characteristic IR absorptions of polysaccharides [37]. The strong band in the region of $1000-1200 \mathrm{~cm}^{-1}$ was attributed to the $\mathrm{C}-\mathrm{O}-\mathrm{C}$ and $\mathrm{C}-\mathrm{OH}$ bands in the IR spectrum, the peak of $1033.51 \mathrm{~cm}^{-1}$ suggests that the characteristic sugar moieties were of pyranose configuration [36]. Furthermore, no absorption peak was observed at $1740 \mathrm{~cm}^{-1}$, which indicates the absence of uronic acids in the polysaccharide structure [37]. This result further suggest that RAMP is a neutral polysaccharide.

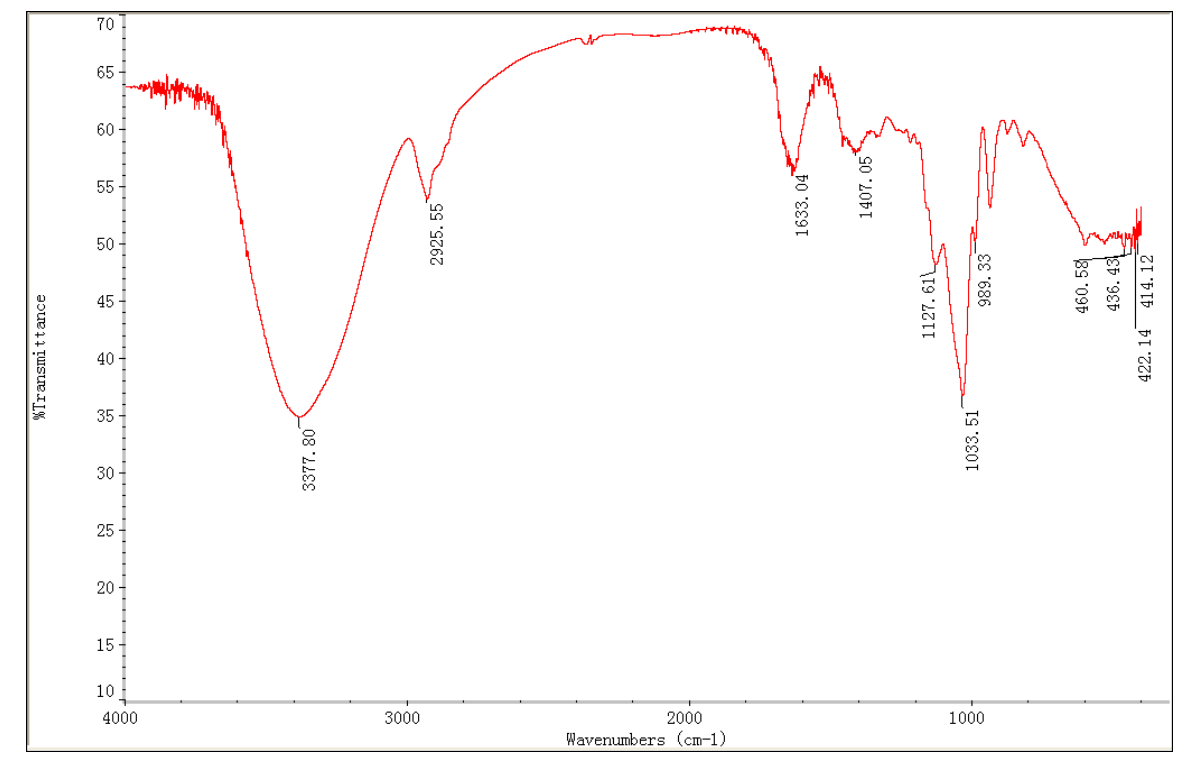

Figure 5. The FT-IR spectrum of RAMP.

\section{Experimental Section}

\subsection{Materials}

The rhizoma of Atractylodes macrocephala was purchased from the herb market of Pan'an Country, Zhejiang Province, China. It was authenticated by Professor Jinbao Pu (Zhejiang Academy of Traditional Chinese Medicine).

\subsection{Chemical and Apparatus}

The cellulase from Trichoderma viride (10,000 U/mg, lot\#: C10008391)) was obtained from Shanghai Macklin Biochemical Co., Ltd. (Shanghai, China). D-Glucose and D-galacturonic acid (110833-200503, 111646-200301) were supplied by the National Institutes for Food and Drug Control (Beijing, China). Albumin (Bovine Serum) (10021008) was purchased from Shanghai Shenhang Biological Technology Co., Ltd. (Shanghai, China). 2,2-Diphenyl-1-picrylhydrazyl (DPPH; 100100723) was purchased from Sigma-Aldrich Chemical Company (St. Louis, MO, USA). All solvents and chemicals were at least of analytical grade and obtained from Sinopharm Chemical Reagent Co., Ltd. (Shanghai, China). 
All UAEE experiments were carried out in an ultrasonic device (JK-300DB, Jiangsu, China) with a usable capacity of $10 \mathrm{~L}$ working at a frequency of $40 \mathrm{kHz}$ and an ultrasound power of $100 \mathrm{~W}$ to 300 W. A centrifuge (Eppendorf 5415D, Hamburg, Germany) was used for the separation of the extract from the matrix residue. A rotary evaporator (Buchi R-210, Flawil, Switzerland) was used for the concentration of extracts. A UV-visible spectrophotometer (Varian Cary-100, Palo Alto, CA, USA) was used for the analysis of the carbohydrate content, protein content and uronic acid content of the RAMP. A microplate spectrophotometer (Biotek Powerwave XS, Winooski, VT, USA) was used for the analysis of DPPH free radical scavenging activity and a FT-IR spectrometer (Thermo Fisher Nicolet iS10, Waltham, MA, USA) was used for FT-IR spectra analysis of RAMP.

\subsection{Methods}

\subsubsection{UAEE Procedure}

The herb material was reduced to a coarse powder with the help of a suitable grinder and passed through a 100 mesh screen. About $200 \mathrm{~g}$ of the dry rhizoma powder was doubly extracted with petroleum ether (boiling point: $60-90{ }^{\circ} \mathrm{C}$ ) at $90{ }^{\circ} \mathrm{C}$ for $3 \mathrm{~h}$ each time and then pretreated in a Soxhlet extractor with $80 \%$ ethanol twice to remove lipids, some colored materials, monosaccharides and oligosaccharides [38]. The residue was then filtered and vacuum dried at $60{ }^{\circ} \mathrm{C}$ for $12 \mathrm{~h}$ for the following UAEE and conventional extraction.

Pretreated powder $(1 \mathrm{~g})$ was doubly extracted with cellulase solution $(30 \mathrm{~mL}$, using NaAc-HAc buffer system as our extracting solvent to adjust the $\mathrm{pH}$ at 4.6) at the given concentration (ratio of water to material $30 \mathrm{~mL} / \mathrm{g}$ ). The extraction time, extraction temperature, cellulase concentration and ultrasonic power was set according to the experimental design. After removing the matrix residue by centrifuge, the extraction solution was incorporated and concentrated to one-fifth of the initial volume using a rotary evaporator at $65{ }^{\circ} \mathrm{C}$ under reduces pressure. The concentrate was precipitated with the addition of anhydrous ethanol to a final concentration of $80 \%(v / v)$ and kept at $4{ }^{\circ} \mathrm{C}$ for $12 \mathrm{~h}$. The precipitate was collected and deproteinated by the Sevage reagent (1-butanol/chloroform, $v / v=1: 4)$ [39]. After mixing the water solution of polysaccharides and Sevage reagent together $(v / v=5: 1)$, vibrated for $15 \mathrm{~min}$ and placed for $2 \mathrm{~h}$ to separating the denatured protein. The process was repeated three times and the product obtained then dried to get RAMP.

\subsubsection{Conventional Procedure}

Hot water extraction (HWE), ultrasonic-assisted extraction (UAE) and enzyme-assisted extraction (EAE) of RAMP were also done to serve as the referance extraction methods. The specific conditions of the different extraction processes are listed in Table 4. All the extracts was obtained and treated according to the procedure mentioned in Section 3.3.1, and both of the yield and DPPH scavenging percentage were determinated.

Table 4. The differrent extraction process of RAMP.

\begin{tabular}{cccccc}
\hline \multirow{2}{*}{ Extraction Processes } & \multicolumn{5}{c}{ Extraction Conditions } \\
\cline { 2 - 6 } & A & B & C & D & E \\
\hline HWE1 & - & - & 90 & 58 & 7.0 \\
HWE2 & - & - & 180 & 80 & 7.0 \\
EAE & 1.95 & - & 90 & 58 & 4.6 \\
UAE & - & 225 & 90 & 58 & 4.6 \\
UAEE & 1.95 & 225 & 90 & 58 & 4.6 \\
\hline
\end{tabular}

A: cellulase concentration (\%), B: ultrasonic power (W), C: extraction time (min), D: extraction temperature $\left({ }^{\circ} \mathrm{C}\right)$, E: $\mathrm{pH}$. 


\subsubsection{Determination of the Yield of RAMP}

The content of RAMP was measured by the phenol-sulfuric acid method [40] using D-glucose as a standard. The yield (\%) of RAMP was then calculated as follows:

$$
\mathrm{Y}_{1}(\%)=\frac{\mathrm{C}}{\mathrm{W}} \times 100 \%
$$

where $\mathrm{Y}_{1}$ is the yield of RAMP, $\mathrm{C}$ is the weight of polysaccharides and $\mathrm{W}$ is the weight of raw material.

\subsubsection{Determination of Antioxidant Acitivity of RAMP}

The antioxidant activity was studied through the evaluation of the free radical-scavenging effect on the DPPH radical, which was measured by the procedure described previously [41] with slight modification. Briefly, ascorbic acid $(\mathrm{Vc})$ was used as the control, and $30 \mu \mathrm{L}$ of RAMP solutions $(0.1 \%$ in water) or control were mixed with $170 \mu \mathrm{L}$ of the ethanolic DPPH $(0.025 \mathrm{~g} / \mathrm{L})$. The mixture was shaken vigorously and incubated at $25{ }^{\circ} \mathrm{C}$ in the dark for $30 \mathrm{~min}$. Absorption of the samples was measured on the microplate spectrophotometer at $517 \mathrm{~nm}$. The scavenging percentage was calculated as follows:

$$
\mathrm{Y}_{2}(\%)=\frac{\mathrm{A}_{c}-\left(\mathrm{A}_{i}-\mathrm{A}_{j}\right)}{\mathrm{A}_{c}} \times 100 \%
$$

where $Y_{2}$ is the scavenging percentage of RAMP, $\mathrm{A}_{c}$ is the absorbance of DPPH solution without sample, $\mathrm{A}_{i}$ is the absorbance of the sample mixed with DPPH solution and $\mathrm{A}_{j}$ is the absorbance of the sample without DPPH solution.

\subsubsection{Experimental Design}

\section{Single Factor Experimental Design}

The single factor experiment was performed in a designed conditions. During the optimization of experimental factors, one factor was changed while the other factors kept constant in each experiment. In this study, four factors including extraction time, extraction temperature, cellulase concentration and ultrasonic power were selected for the single factor experiments. In detail, the extraction time range was from $10 \mathrm{~min}$ to $90 \mathrm{~min}$, the extraction temperature ranged from $30^{\circ} \mathrm{C}$ to $70{ }^{\circ} \mathrm{C}$, the cellulase concentration ranged from $0.5 \%$ to $2.5 \%(w / v)$ and the ultrasonic power range was from $100 \mathrm{~W}$ to $300 \mathrm{~W}$. The effect of each factor was evaluated by determining the extraction yield of RAMP. All the experiments were repeated three times.

\section{Box-Behnken Design}

On the basis of the single factor experiments, a Box-Behnken design (BBD) with four factors and three levels was used for the further optimization of the UAEE conditions. Four independent variables including extraction time, extraction temperature, cellulase concentration and ultrasonic power were designated as $X_{1}, X_{2}, X_{3}$ and $X_{4}$, respectively. The ranges of values were based on the results of the preliminary experiments, as shown in Table 5 . The response variables were the extraction yield of RAMP $\left(Y_{1}\right)$ and the DPPH scavenging percentage $\left(Y_{2}\right)$. As shown in Table 1, there were a total 29 runs based on the BBD with five center points performed in random order with triplicates in each run. 
Table 5. Independent variables and their levels in Box-Behnken design

\begin{tabular}{ccccc}
\hline \multirow{2}{*}{ Independent variables } & \multirow{2}{*}{ Symbol } & \multicolumn{3}{c}{ Level } \\
\cline { 3 - 5 } & & $\mathbf{- 1}$ & $\mathbf{0}$ & $\mathbf{1}$ \\
\hline Extraction time $(\mathrm{min})$ & $\mathrm{X}_{1}$ & 10 & 50 & 90 \\
Extraction temperature $\left({ }^{\circ} \mathrm{C}\right)$ & $\mathrm{X}_{2}$ & 30 & 50 & 70 \\
Cellulase concentration $(\%)$ & $\mathrm{X}_{3}$ & 0.5 & 1.5 & 2.5 \\
Ultrasonic power $(\mathrm{W})$ & $\mathrm{X}_{4}$ & 100 & 200 & 300 \\
\hline
\end{tabular}

\subsubsection{Statistical Analysis and Optimization}

The parameters of the response equation and analysis of variance (ANOVA) were performed by Design Expert Software (Version 8.0.6). A second order polynomial model used to fit the response to the independent variables is shown below:

$$
Y=\beta_{0}+\sum_{i=1}^{3} \beta_{i} X_{i}+\sum_{i=1}^{3} \beta_{i i} X_{i}^{2}+\sum \sum_{i<j}^{3} \beta_{i j} X_{i} X_{j}
$$

where $Y$ is the response, $\beta_{0}$ is the intercept parameter and $\beta_{i}, \beta_{i i}, \beta_{i j}$ are the coefficients of the parameters for linear, squared and interaction effects, respectively.

The statistical significance for each term in the polynomial was evaluated by computing the $F$-value at a probability $p$ of 0.05 . The regression coefficients were then used to make statistical calculations and generate contour maps from the regression models. However, for multi-response, a desirability function approach can be used to transformed several response variables into a desirabitity function, which can be optimized by univariate techniques. A modified desirability approach, proposed by Derringer and Suich [22] is defined as:

$$
D=\left(d_{1}^{w_{1}} d_{2}^{w_{2}} d_{3}^{w_{3}} d_{4}^{w_{4}} d_{n}^{w_{n}}\right)^{1 / \sum w_{i}}
$$

where $w_{i}$ is the relative weight of the $i$ th response, $D$ is the overall desirability, and $d_{i}$ is an individual response desiralibity. Then, the optimal setting is determined by the following, which is described previously $[42,43]$.

$$
d i= \begin{cases}0 & Y_{i} \leqslant Y_{i-\min } \\ {\left[\frac{Y_{i}-Y_{i-\min }}{Y_{i-\max }-Y_{i-\min }}\right]^{r}} & Y_{i-\min }<Y_{i}<Y_{i-\max } \\ 1 & Y_{i} \geqslant Y_{i-\max }\end{cases}
$$

where $Y_{i}$ is the response value, $Y_{i-\min }$ is the minimum acceptable value for response $i, Y_{i-\max }$ is the maximum acceptable value for response $i$, and $r$ is a weight used to determine scale of desirability and equals 1 in this work.

\subsubsection{Preliminary Characterization of RAMP}

The total neutral carbohydrate content was determinated by the phenol-sulfuric acid colorimetric method described in Section 3.3.3. The protein content was measured by Coomassie brilliant blue reaction [44] and the UV scanning spectrum at $280 \mathrm{~nm}$. Uronic acid content was determinated by the $m$-hydroxydiphenyl method using D-galacturonic acid as standard [45]. The characteristic absorption of RAMP was identified by the FT-IR spectrum [36]. The RAMP powder was mixed with KBr powder, ground and pressed for FT-IR measurement in the wavenumber range from 400 to $4000 \mathrm{~cm}^{-1}$.

\section{Conclusions}

An UAEE process has been optimized for effective extraction of RAMP with high antioxidant activity. The maximum $\mathrm{D}$ value of 0.375 , along with the maximum yield $(13.73 \%)$ and scavenging 
percentage $(62.18 \%)$ were achieved after an extraction time of $82.04 \mathrm{~min}$, using an extraction temperature of $58.67{ }^{\circ} \mathrm{C}$, a cellulase concentration of $1.99 \%$ and $230.67 \mathrm{~W}$ of ultrasonic power. These values were further validated by confirmatory experiments to see the efficacy of the model predictability and found to be in good agreement with the predicted values. Compared to other extraction methods, both the extraction yield and DPPH scavenging percentage of RAMP obtained by UAEE was favorable and the method appeared to be time-saving and of high efficiency. These results demostrated that UAEE is an appropriate and effective extraction technique for RAMP. Moreover, RSM with DF approach has been proved to be adequate for the design and optimization of the extraction parameters for RAMP. This works offer a wide range of implications for guiding the design and operation of polysaccharide extraction processes and may have a great impact on the polysaccharide extraction industries.

Acknowledgments: We greatly acknowledge the financial support from the Traditional Chinese Medicine of Zhejiang Province Science and Technology Plan Project (No. 2013ZA006). We are also grateful for the Construction of Key Laboratory of Research and Development of Chinese Medicine of Zhejiang Province (No.2008F3036).

Author Contributions: Bo-Hou Xia, Pan Xu and Jin-Bao Pu designed the research and wrote the paper, Yi-Juan $\mathrm{Hu}$ and Hong-Jian Zhang analyze the experiment results, Jing Chen, Jie Zhou and Wei-Qing Liang performed the research. All authors read and approved the final manuscript.

Conflicts of Interest: The authors declare no conflict of interest.

\section{References}

1. Yao, C.M.; Yang, X.W. Bioactivity-guided isolation of polyacetylenes with inhibitory activity against NO production in LPS-activated RAW264.7 macrophages from the rhizomes of Atractylodes macrocephala. J. Ethnopharmacol. 2014, 151, 791-799. [CrossRef] [PubMed]

2. Chinese Pharmacopoeia Commission. Pharmacopeia of People's Republic of China; Chemical Industry Press: Beijing, China, 2010; Volume 1, p. 95.

3. Chen, Z.L. The Acetylenes from Atractylodes macrocephala. Planta Med. 1987, 53, 493-494. [CrossRef] [PubMed]

4. Kitajima, J.; Kamoshita, A.; Ishikawa, T.; Takano, A.; Fukuda, T.; Isoda, S.; Ida, Y. Glycosides of Atractylodes ovata. Chem. Pharm. Bull. 2003, 51, 1106-1108. [CrossRef] [PubMed]

5. Dong, H.; He, L.; Huang, M.; Dong, Y. Anti-inflammatory components isolated from Atractylodes macrocephala Koidz. Nat. Prod. Res. 2008, 22, 1418-1427. [CrossRef] [PubMed]

6. Shan, G.S.; Zhang, L.X.; Zhao, Q.M.; Xiao, H.B.; Zhuo, R.J.; Xu, G.; Jiang, H.; You, X.M.; Jia, T.Z. Metabolomic study of raw and processed Atractylodes macrocephala Koidz by LC-MS. J. Pharm. Biomed Anal. 2014, 98, 74-84. [CrossRef] [PubMed]

7. Liu, J.; Chen, X.; Yue, C.; Hou, R.; Chen, J.; Lu, Y.; Li, X.; Li, R.; Liu, C.; Gao, Z.; et al. Effect of selenylation modification on immune-enhancing activity of Atractylodes macrocephala polysaccharide. Int. J. Biol. Macromol. 2015, 72, 1435-1440. [CrossRef] [PubMed]

8. Xie, F.; Li, Y.; Su, F.; Hu, S. Adjuvant effect of Atractylodis macrocephalae Koidz. polysaccharides on the immune response to foot-and-mouth disease vaccine. Carbohydr. Polym. 2012, 87, 1713-1719. [CrossRef]

9. Xie, F.; Sakwiwatkul, K.; Zhang, C.; Wang, Y.; Zhai, L.; Hu, S. Atractylodis macrocephalae Koidz. polysaccharides enhance both serum IgG response and gut mucosal immunity. Carbohydr. Polym. 2013, 91, 68-73. [CrossRef] [PubMed]

10. Shi, N.; Su, J.; Yang, Z.B.; Lv, G.Y.; Chen, S.H. Antioxidantive effect of polyasaccharides from Atractylodes macrocephalaon in D-galactose-induced aging mice. Chin. J. New Drugs. 2014, 23, 577-581.

11. Hu, W.X.; Xiang, Q.; Wen, Z.; He, D.; Wu, X.M.; Hu, G.Z. Neuroprotective effect of Atractylodes macrocephala polysaccharides in vitro on neuronal apoptosis induced by hypoxia. Mol. Med. Rep. 2014, 9, 2573-2581. [PubMed]

12. Shan, J.J.; Tian, G.Y. Studies on physico-chemical properties and hypoglycemic activity of complex polysaccharide AMP-B from Atractylodes macrocephala Koidz. Acta Pharm. Sinica 2003, 38, 438-441.

13. Zhang, P.J.; Jin, C.; Lang, J. Effect of Atractylodes macrocephalaon polysaccharides for reducing liver ischemia/reperfusion injury in rats after orthotopic liver autotransplantation. Chin. J. Integr. Tradit. West. Med. 2010, 30, 1193-1196. 
14. Zhao, Z.Y.; Zhang, Q.; Li, Y.F.; Dong, L.L.; Liu, S.L. Optimization of ultrasound extraction of Alisma orientalis polysaccharides by response surface methodology and their antioxidant activities. Carbohydr. Polym. 2015, 119, 101-109. [CrossRef] [PubMed]

15. Lai, J.; Wang, H.; Wang, D.; Fang, F.; Wang, F.; Wu, T. Ultrasonic extraction of antioxidants from Chinese sumac (Rhus typhina L.) fruit using response surface methodology and their characterization. Molecules 2014, 19, 9019-9032. [CrossRef] [PubMed]

16. Moura, J.M.L.N.; Campbell, K.; Mahfuz, A.; Jung, S.; Glatz, C.E.; Johnson, L. Enzyme-assisted aqueous extraction of oil and protein from soybeans and cream de-emulsification. J. Am. Oil Chem. Soc. 2008, 85, 985-995. [CrossRef]

17. Liu, Y.; Gong, G.; Zhang, J.; Jia, S.; Li, F.; Wang, Y.; Wu, S. Response surface optimization of ultrasound-assisted enzymatic extraction polysaccharides from Lycium barbarum. Carbohydr. Polym. 2014, 110, 278-284. [CrossRef] [PubMed]

18. Wang, T.; Li, C.Q.; Zhang, H.; Li, J.W. Response surface optimized extraction of 1-deoxynojirimycin from mulberry leaves (Morus alba L.) and preparative separation with resins. Molecules 2014, 19, 7040-7056. [CrossRef] [PubMed]

19. Salmasnia, A.; Baradaran kazemzadeh, R.; Mohajer Tabrizi, M. A novel approach for optimization of correlated multiple responses based on desirability function and fuzzy logics. Neurocomputing 2012, 91, 56-66. [CrossRef]

20. Khuri, A.; Cornell, J. Response Surfaces: Designs and Analyses, 2nd ed.; Dekker: New York, NY, USA, 1996; Volume 12, pp. 72-75.

21. He, Z.; Zhu, P.F.; Park, S.H. A robust desirability function method for multi-response surface optimization considering model uncertainty. Eur. J. Oper. Res. 2012, 221, 241-247. [CrossRef]

22. Derringer, G. A Balancing Act: Optimizing a Product's Properties; Quality Press: Perth, Australia, 1994; Volume 27, pp. 51-58.

23. Derringer, G.; Suich, R. Simultaneous optimization of several response variables. J. Qual. Technol. 1980, 12, 214-219.

24. Islam, M.A.; Sakkas, V.; Albanis, T.A. Application of statistical design of experiment with desirability function for the removal of organophosphorus pesticide from aqueous solution by low-cost material. J. Hazard. Mater. 2009, 170, 230-238. [CrossRef] [PubMed]

25. Heidari, H.; Razmi, H. Multi-response optimization of magnetic solid phase extraction based on carbon coated $\mathrm{Fe}_{3} \mathrm{O}_{4}$ nanoparticles using desirability function approach for the determination of the organophosphorus pesticides in aquatic samples by HPLC-UV. Talanta 2012, 99, 13-21. [CrossRef] [PubMed]

26. Jeong, I.J.; Kim, K.J. An interactive desirability function method to multiresponse optimization. Eur. J. Oper. Res. 2009, 195, 412-426. [CrossRef]

27. Candioti, L.V.; de Zan, M.M.; Camara, M.S.; Goicoechea, H.C. Experimental design and multiple response optimization. Using the desirability function in analytical methods development. Talanta 2014, 124, 123-138. [CrossRef] [PubMed]

28. Chen, X.P.; Tang, Q.C.; Chen, Y.; Wang, W.X.; Li, S.B. Simultaneous extraction of polysaccharides from Poria cocos by ultrasonic technique and its inhibitory activities against oxidative injury in rats with cervical cancer. Carbohydr. Polym. 2009, 79, 409-413. [CrossRef]

29. Chen, F.; Sun, Y.; Zhao, G.; Liao, X.; Hu, X.; Wu, J.; Wang, Z. Optimization of ultrasound-assisted extraction of anthocyanins in red raspberries and identification of anthocyanins in extract using high-performance liquid chromatography-mass spectrometry. Ultrason. Sonochem. 2007, 14, 767-778. [CrossRef] [PubMed]

30. Fu, X.Y.; Xue, C.H.; Miao, B.C.; Li, Z.J.; Gao, X.; Yang, W.G. Characterization of proteases from the digestive tract of sea cucumber (Stichopus japonicus): High alkaline protease activity. Aquaculture 2005, 246, 321-329. [CrossRef]

31. Ticar, B.F.; Rohmah, Z.; Ambut, C.V.; Choi, Y.J.; Mussatto, S.I.; Choi, S.D. Enzyme-assisted extraction of anticoagulant polysaccharide from Liparis tessellates eggs. Int. J. Biol. Macromol. 2015, 74, 601-607. [CrossRef] [PubMed]

32. Rhein-Knudsen, N.; Ale, M.T.; Meyer, A.S. Seaweed hydrocolloid production: An update on enzyme assisted extraction and modification technologies. Mar. Drugs 2015, 13, 3340-3359. [CrossRef] [PubMed]

33. Tahmouzi, S. Optimization of polysaccharides from Zagros oak leaf using RSM: Antioxidant and antimicrobial activities. Carbohydr. Polym. 2014, 106, 238-246. [CrossRef] [PubMed] 
34. Kuo, C.H.; Chen, B.Y.; Liu, Y.C.; Chang, C.M.; Deng, T.S.; Chen, J.H.; Shieh, C.J. Optimized ultrasound-assisted extraction of phenolic compounds from Polygonum cuspidatum. Molecules 2013, 19, 67-77. [CrossRef] [PubMed]

35. Liu, J.H.; Ren, H.L.; Guan, B.; Zheng, W.C.; Gao, F. Response surface optimization of extraction process of Atractylodes polysaccharide. Chin. Tradit. Pat. Med. 2008, 30, 667-670.

36. Yi, P.; Li, N.; Wan, J.B.; Zhang, D.; Li, M.; Yan, C. Structural characterization and antioxidant activity of a heteropolysaccharide from Ganoderma capense. Carbohydr. Polym. 2015, 121, 183-189. [CrossRef] [PubMed]

37. Pei, J.J.; Wang, Z.B.; Ma, H.L.; Yan, J.K. Structural features and antitumor activity of a novel polysaccharide from alkaline extract of Phellinus linteus mycelia. Carbohydr. Polym. 2015, 115, 472-477. [CrossRef] [PubMed]

38. Zhao, Z.; Xu, X.; Ye, Q.; Dong, L. Ultrasound extraction optimization of Acanthopanax senticosus polysaccharides and its antioxidant activity. Int. J. Biol. Macromol. 2013, 59, 290-294. [CrossRef] [PubMed]

39. Savag, M.G.; Lackman, D.B.; Smolens, J. The isolation of the components of streptococcal nucleoproteins in serologically active from. J. Biol. Chem. 1938, 124, 425-436.

40. Kettlitz, B. Carbohydrate Analysis: A Practical Approach; Chaplin, M.F., Kennedy, J.E., Eds.; IRL Press: Oxford, UK, 1986; p. 3.

41. Vallverdu-Queralt, A.; Regueiro, J.; Martinez-Huelamo, M.; Rinaldi Alvarenga, J.F.; Leal, L.N.; Lamuela-Raventos, R.M. A comprehensive study on the phenolic profile of widely used culinary herbs and spices: Rosemary, thyme, oregano, cinnamon, cumin and bay. Food Chem. 2014, 154, 299-307. [CrossRef] [PubMed]

42. Costa, N.R.; Lourenco, J.; Pereira, Z.J. Desirability function approach: A review and performance evaluation in adverse conditions. Chemometr. Intell. Lab. 2011, 107, 234-244. [CrossRef]

43. Shi, X.Y.; Li, W.W.; Yu, H.Q. Optimization of $\mathrm{H}_{2}$ photo-fermentation from benzoate by Rhodopseudomonas palustris using a desirability function approach. Int. J. Hydrog. Energy 2014, 39, 4244-4251. [CrossRef]

44. Bradford, M.M. A rapid and sensitive method for the quantitation of microgram quantities of protein utilizing the principle of protein-dye binding. Anal. Biochem. 1976, 72, 248-254. [CrossRef]

45. Blumenkrantz, N.; Asboe-Hansen, G. New method for quantitative determination of uronic acids. Anal. Biochem. 1973, 54, 484-489. [CrossRef]

Sample Availability: Samples of the compounds are available from the authors.

(C) 2015 by the authors; licensee MDPI, Basel, Switzerland. This article is an open access article distributed under the terms and conditions of the Creative Commons by Attribution (CC-BY) license (http://creativecommons.org/licenses/by/4.0/). 